\title{
Determination of age and gender using condylar height and coronoid height- An orthopantomographic study
}

\author{
Aditi Ramesh ${ }^{1}$, Nagalaxmi Velpula ${ }^{2}$, Roshni Tandon ${ }^{3, *}$, Faisal Taiyebali Zardi ${ }^{4}$, Madhuri Kanakagiri ${ }^{5}$ \\ ${ }^{\mathbf{1}}$ Assistant Professor, ${ }^{2}$ Professor and Head, ${ }^{3,5}$ Post Graduate, ${ }^{4}$ Reader, Dept. of Oral medicine and Radiology, Sri Sai College of \\ Dental Surgery, Vikarabad, Telangana, India \\ *Corresponding Author: Roshni Tandon \\ Email: roshtandon26@gmail.com
}

\begin{abstract}
Introduction: The determination of age and gender in remnants of skull is important for medico-legal cases, especially where the bodies have been injured beyond identification as seen usually in cases of mass disaster. Panoramic radiographs are frequently used in routine dental practice to visualize the complete maxillo-mandibular region, temporo-mandibular joint and bilateral vital structures which are recorded on a single film. Hence, using digital panoramic radiographs this study was conducted in Telangana population to evaluate the usefulness of different linear measurements of ramus in determination of age and gender.

Materials and Methods: 150 panoramic images of dentate subjects with an age ranging from 20-70yrs old were selected for the present study. For every panoramic image measurements were performed bilaterally resulting in a total of 300 rami being assessed. The digital panoramic images were saved in JPEG. File format and exported to the Care stream dental imaging software where the linear measurements were performed. The measurements were made using condylar-ramus and coronoid-ramus height. These measurements were subjected to statistical analysis.

Results: It was seen that the Condyle to Gonion (CG) and Coronoid to Gonion (CoG) values is greater in males than in females with high significance. On comparison of the mean values of $\mathrm{CG}$ and $\mathrm{CoG}$ amongst the 3 age groups there was a significant difference in the mean $\mathrm{CG}$ values but not in the mean $\mathrm{CoG}$ values.

Conclusion: The ramus height measurements on digital panoramic radiogrpahs can be used in the determination of age and gender.
\end{abstract}

Keywords: Age determination, Gender determination, Orthopantomograph, Condylar height, Coronoid height.

\section{Introduction}

The determination of age and gender in remnants of skull is important for medico-legal cases, especially where the bodies have been injured beyond identification as seen usually in cases of mass disaster. ${ }^{1}$ After pelvis, skull remains the most dimorphic structure. Mandible is a dimorphic, huge and a strong bone, playing a crucial role in cases where the intact skull is not found. $^{2}$ Mandible exhibits many morphological and anatomical changes with gender and advancement in age. ${ }^{3}$

Stages of mandibular development; growth rate and the duration of the growth are different in both the sexes and hence mandibular ramus can be used in differentiation of the sexes. The form and dimensions of mandibular ramus is affected by masticatory forces which are different in males and females. Inspite of the variability in anatomical landmarks of the mandible, numerous studies have been carried out using ramus as a standard of measurement for age and sex determination. ${ }^{4}$

Panoramic radiographs are frequently used in routine dental practice to visualize the complete maxillo-mandibular region, temporomandibular joint and bilateral vital structures which are recorded on a single film. ${ }^{5,6}$ Hence, using digital panoramic radiographs this study was conducted in Telangana population to evaluate the usefulness of different linear measurements of ramus in determination of age and gender. $^{2}$
The present study aims to determine if mandibular parameters measured from panoramic radiographs, can be used to determine a correlation with an individual's age and gender in dentate subjects in Telangana population by estimation of condylar height and coronoid height of mandible in panoramic radiographs.

\section{Materials and Methods}

150 digital panoramic images taken previously for various diagnostic procedures were evaluated for the present study. The panoramic images were acquired using care stream CS 8000 instrumentation, dental. The exposure parameters were $71 \mathrm{kVp}, 6.1 \mathrm{~mA}$ and 13.2 seconds according to the patients age and size.

150 panoramic images of dentate subjects with an age ranging from 20-70yrs old were selected for the present study. For every panoramic image measurements were performed bilaterally resulting in a total of 300 rami being assessed. The digital panoramic images were saved in JPEG. File format and exported to the Care stream dental imaging software where the linear measurements were performed. The study was held at the Department of Oral Medicine and Radiology, Sri Sai College of Dental Surgery, Vikarabad.

Method of Measurement of Parameters: After image calibration, the following mandibular ramus linear measurements were performed in millimetres.

For standardisation, a reference line was drawn along the posterior border and along the inferior border 
of mandible with the point of intersection at the gonion was taken.

1. Condylar-ramus height: the distance from the highest point of the condyle to the point of intersection at the gonion (CG).

2. Coronoid-ramus height: The distance from the coronion to the point of intersection at the gonion (CoG).

The observer was blinded to the sex and age of the individual. The mean values taken were calculated and subjected to statistical analysis.

\section{Inclusion Criteria}

1. OPG with all teeth present with or without third molars (dentate).

2. Age range from 20-70 years.

Exclusion Criteria:

1. Good quality OPG without any exposure or positioning errors.

2. Presence of any pathological lesions.

3. Presence of any fractures.

4. Presence of any deformity.

\section{Statistical Analysis}

The results of this study was statically analyzed with the help of SPSS 20.0, using ONE-WAY ANNOVA to compare the mean values of $\mathrm{CG}$ and $\mathrm{CoG}$ amongst 3 age groups and independent t-test was used to compare the mean values of $\mathrm{CG}$ and $\mathrm{CoG}$ amongst males and females. Tukey's post hoc analysis was also used to compare mean CG values amongst the 3 age groups.

\section{Results}

The Mean \pm SD value of $\mathrm{CG}$ in_females is $54.15 \pm 7.21$ and in males is 59.03 \pm 6.28 . The MEAN \pm SD value of $\mathrm{CoG}$ in females is $50.04 \pm 4.65$ and in males is $52.88+6.19$. It was seen that the $\mathrm{CG}$ and CoG values is greater in males than in females with high significance $(\mathrm{p}<0.001)$ (Table 1$)$.

The Mean \pm SD CG value in the age group of $20-40$ years is $59.23 \pm 7.27,41-60$ years is $55.87 \pm 7.12$ and 60 years above is $54.65 \pm 4.53$. The Mean \pm SD CoG value in the age group of $20-40$ years is $50.86 \pm 5.70,41-60$ years is $53.47 \pm 5.37$ and 60 years above is $50.93+4.09$. When One -way ANNOVA was used to compare the mean values of $\mathrm{CG}$ and $\mathrm{CoG}$ amongst the 3 age groups there was a significant difference the mean $C G$ values but not in the mean $\mathrm{CoG}$ values. On further Tukey's post hoc analysis the mean $C G$ values in the 20-40 age group was significantly greater than the $60+$ year age group. (Table 2).

Table 1: The Mean + SD value of $C G$ in females and males

\begin{tabular}{|l|c|c|c|}
\hline \multirow{2}{*}{ Parameters } & \multicolumn{2}{|c|}{ MEAN \pm SD } & \multirow{2}{*}{ p-value } \\
\cline { 2 - 3 } & \multicolumn{2}{|c|}{ Females Males } & $<0.001(\mathrm{~S})$ \\
\hline $\mathrm{CG}$ & $54.15 \pm 7.21$ & $59.03 \pm 6.28$ & $<0.001(\mathrm{~S})$ \\
\hline $\mathrm{CoG}$ & $50.04 \pm 4.65$ & $52.88 \pm 6.19$ & \\
\hline
\end{tabular}

Table 2: The Mean \pm SD CG value in the age group of 20-40 years, 41-60 years and above 60 years

\begin{tabular}{|c|c|c|c|c|c|}
\hline & \multicolumn{3}{|c|}{ MEAN \pm SD } & & \\
\hline Parameters & $20-40 y r s$ & 41-60yrs & 60yrs above & p-value & POST-HOC \\
\hline CG & $59.23 \pm 7.27$ & $55.87 \pm 7.12$ & $54.65 \pm 4.53$ & 0.04 & $20-40>41-60$ \\
\hline $\mathrm{CoG}$ & $50.86 \pm 5.70$ & $53.47 \pm 5.37$ & $50.93+4.09$ & 0.06 & NA \\
\hline
\end{tabular}

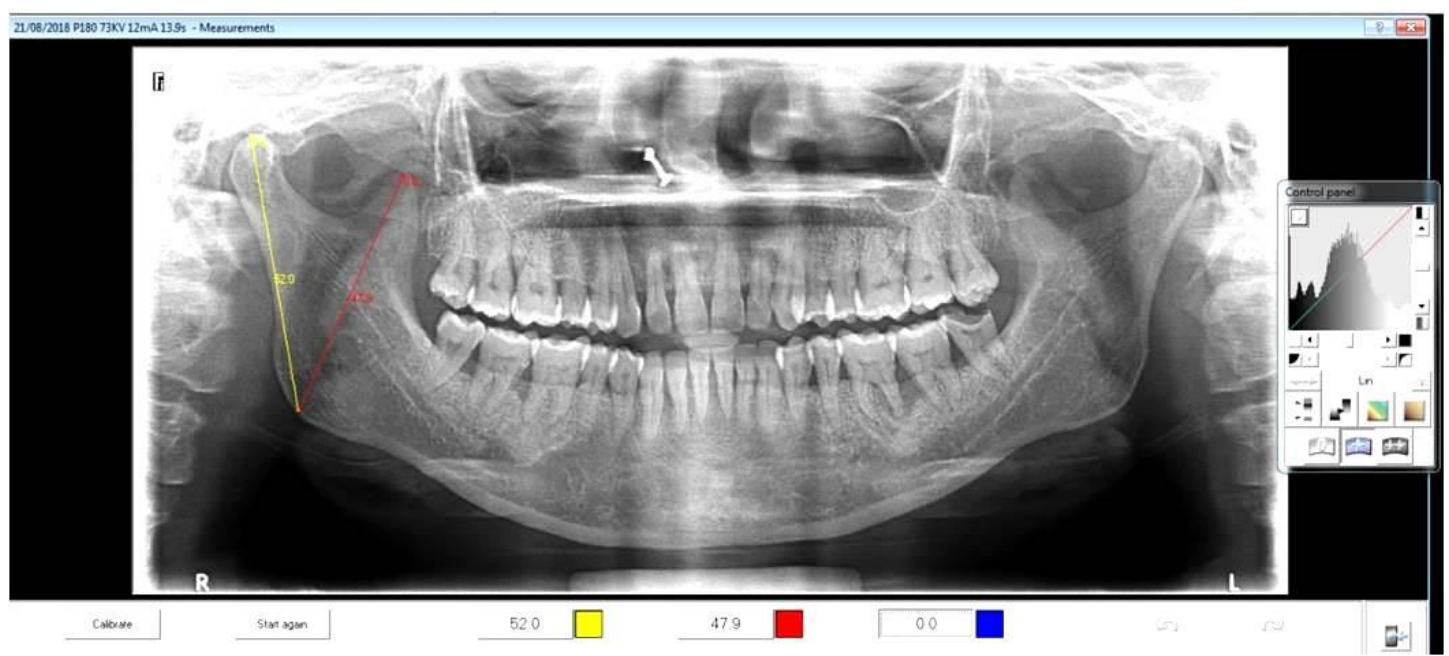

Fig. 1: Measurement of condylar to gonion (CG) (yellow line) and coronoid to gonion (CoG) (red line) 


\section{Discussion}

Determination of age and gender plays a very important role in the identification of an individual. Age and sex are equally dependent on each other. ${ }^{6}$ Of all the facial bones, mandible is the strongest and is used for identification of age and sex by forensic odontologist. ${ }^{78}$ Mandible is made up of dense cortical bone and shows sexual dimorphism which occurs mostly due to the genetic predisposition of males and females during the development period. The size, strength and angulation of mandible are effected by the muscles of mastication and the masticatory forces. ${ }^{9}$ Males have a greater muscular mass applying more amount of mechanical forces on the mandible than in females. Young adult males have greater bite forces when compared to females thus responsible for greater muscle mass in males. This differentiation in the muscle mass contributes to sexual dimorphism. In few instances, greater muscle mass in temporalis muscle may be due to elongated coronoid process of the mandible in males. ${ }^{10}$

Age and sex determination is one of the important hallmark of forensic odontology and anthropology. Different morphological, metrical and biochemical methods have been used for the determination of age and sex. Of all these, metrical methods are reproducible and show less errors whereas morphological methods produce inter-examiner variability. The biochemical methods are complicated and the most expensive among all the three methods. ${ }^{11}$

Panoramic radiographs can be used for anatomical measurements. The main advantages of the panoramic images include less radiation dose, less time for image acquisition, broad coverage and contrast enhancement. The limitations of this radiographic technique includes geometric distortion and magnification. This technique is sensitive to postioning errors because of the narrow image layer. ${ }^{12}$

In the present study a total of 150 orthopantomographs of dentate subjects were included with an age range of 20-60 years for measuring the CG and $\mathrm{CoG}$ in a total of 300 rami. The measurements of the condylar and coronoid height were measured using the Carestream 8000 instrumentation. It was observed that the $\mathrm{CG}$ and $\mathrm{CoG}$ values were significantly greater in males than in females.

Similarly in a study done by Jyothsna $\mathrm{M}$ et al, ${ }^{5}$ the condylar height in females was $61.32+3.54 \mathrm{~mm}$ and in males it was $68.04+4.20 \mathrm{~mm}$ that is significantly greater in males than in females which was almost similar to that of the present study. Similar findings were noticed in a study done by Sairam et al, ${ }^{13}$ comparing the different mandibular measurements, the condylar height was found to be significant in gender determination with mean in males and females being $65.01 \mathrm{~mm}$ and $59.48 \mathrm{~mm}$ on right side and $65.71 \mathrm{~mm}$ and $59.65 \mathrm{~mm}$ on left side. According to Samantha et al, ${ }^{14}$ similar results were seen in corrsepondance to the present study where the condylar height was found to be significant and the mean values for males is $65.34 \mathrm{~mm}$ and in females it was $61.69 \mathrm{~mm}$. In a study done by Saraswathi $\mathrm{G}$ et al,${ }^{15}$ using CBCT images of 50 males and 50 females with a mean condylar height in males was $65.79 \mathrm{~mm}$ and in females was $61.80 \mathrm{~mm}$ thus concluded that the height of the condyle can be the best parameter.

In the present study the condylar height and coronoid height were measured using care stream 8000 intrumentation and it was observed that the condylar height decreases with age and the coronoid height plays no significance.

In a study done by Noha Saleh Abu-Taleb et al, ${ }^{2}$ a significant positive correlation was found between age and the mandibular linear measurements, regression analysis results showed that coronoid ramus height was a significant indicator for age. This study was not in correlation with the present study.

According to Samantha et al, ${ }^{14}$ similar results were seen in corrsepondance to the present study where the condylar height was found to be significant and the mean values for males is $65.34 \mathrm{~mm}$ and in females it was $61.69 \mathrm{~mm}$ and the coronoid height plays no significant role which was in correlation with our study.

\section{Conclusion}

To conclude, our results were in support with the previous researches that proved mandibular ramus has high sexual dimorphism and can be used for age and sex determination.

The limitations of this study is that it would have been better if the present study used CBCT which has the least distortion but cannot be considered due to its high radiation dose. However, further studies should be conducted using larger samples in telangana population.

\section{References}

1. Jambunath, Usha. "Sex Determination by using Mandibular Ramus and Gonial Angle-a preliminary Comparative study". International Journal of Contemporary Medical Research. 2016;3(11):78.

2. Abu-Taleb NS, El Beshlawy DM. Mandibular ramus and gonial angle measurements as predictors of sex and age in an Egyptian population sample: A digital panoramic study. Journal of Forensic Research. 2015;6(5):1.

3. Sairam V, Potturi GR, Praveen B, Vikas G. Assessment of effect of age, gender, and dentoalveolar changes on mandibular morphology: A digital panoramic study. Contemporary Clinical Dentistry. 2018;9(1):49.

4. Leversha J, McKeough G, Myrteza A, SkjellrupWakefield H, Welsh J, Sholapurkar A. Age and gender correlation of gonial angle, ramus height and bigonial width in dentate subjects in a dental school in Far North Queensland. Journal of Clinical And Experimental Dentistry. 2016;8(1):e49.

5. Jyothsna M, Ranjith K, Sarat G. Determination of gender using condylar height and coronoid height-an orthopantomographic study. 2017;9(1):5a. 
6. Rosing FW, Graw M, Marre B, Ritz-Timme S, Rotschild MA, Rotzcher K, Geserick G. Recommendations for the forensic diagnosis of sex and age from skeletons-HOMO. Journal of Comparative Human Biology. 2007;58:75-89.

7. Saxena S, Sharma P, Gupta N. Experimental studies of forensic odontology to aid in the identification process. Journal of Forensic Dental Sciences. 2010;2(2):69-76.

8. Franklin D. Forensic age estimation in human skeletal remains: Current concepts and future directions legal medicine. Centre for forensic science: Elsevier,2009:1-7.

9. Indira AP, Markande A, David MP. Mandibular Ramus: An indicator for sex determination- A digital radiographic study. Journal of Forensic Dental Science. 2012;4(2):5862.

10. Singh R, Mishra SR, Sushobhana, Passey J, Kumar P et al. Sexual dimorphism in adult human mandible of North Indian origin. 2015;3:82-88.

11. G D'Eyrames, Siiegmund F. Papageorgopoulou C.

Discrimant function analysis versus morphognostic sex determination of 637 crania from the Poschiavoossuary. Bulletinder Schweizerischen Gesellschaftfur Anthropologie. 2009;15(1-2):57-63.
12. Humphrey Lt, Dean MC, Stringer CB. Morphological variation in great ape and modern human mandibles. $J$ Anat. 1999;195:491-513.

13. Sairam V, Geethamalika MV, Kumar PB, Naresh G, Raju GP. Determination of sexual dimorphism in humans by measurements of mandible on digital panoramic radiograph. Contemp Clin Dent. 2016;7:434-9.

14. Byahatti S, Samantha K, Ammanagi R, Tantradi P, Sarang C, Shivpuje P. Sex determination by mandibular ramus: A digital orthopantomographic study. Journal of Forensic Dental Sciences. 2016;8(2):95.

15. Saraswathi G, Kshatri JK, Mahesh K. Sex determination with mandibular ramus- a retrospective study based on cone beam computer tomography. International Journal of Information Research and Review. 2016;3:2328-2329. 